\title{
Evaluation of series of 177 cases of acute gynaecological emergencies in tertiary care hospital
}

\author{
Vrunda Choudhary ${ }^{1}$, Sonali S. Somani ${ }^{2}$, Shashikant G. Somani ${ }^{3} *$, Rajesh Kaul ${ }^{4}$
}

\footnotetext{
${ }^{1}$ Associate Professor, Department of Obstetrics and Gynecology, Kamineni Institute of Medical Science, Narketpally, Nalgonda, Telangana, India

${ }^{2}$ Assistant Professor Department of Obstetrics \& Gynecology, Kamineni Institute of Medical Science, Narketpally, Nalgonda, Telangana, India

${ }^{3}$ Assistant Professor, Department of Physiology, Kamineni Institutes of Medical sciences, Narketpally, Nalgonda, Telangana, India

${ }^{4}$ Professor and Head, Department of Obstetrics and Gynaecology, Kamineni Institute of Medical Science, Nalgonda, Telangana, India
}

Received: 27 April 2016

Accepted: 05 May 2016

\section{*Correspondence:}

Dr. Shashikant G. Somani,

E-mail: drsgsomani@gmail.com

Copyright: () the author(s), publisher and licensee Medip Academy. This is an open-access article distributed under the terms of the Creative Commons Attribution Non-Commercial License, which permits unrestricted non-commercial use, distribution, and reproduction in any medium, provided the original work is properly cited.

\section{ABSTRACT}

Background: Gynecologic emergencies are relatively common and acute pain of pelvic origin is a common symptom necessitating emergency medical evaluation, because late diagnosis, potentially leading to progression to severe morbidity or death, is a matter of concern. The objective of present study is to have an overview of emergency gynecological conditions and their management.

Methods: In present retrospective observational study total 177 cases were analyzed. They were divided into three groups depending on age, adolescent group patients aged 19 year and below (group A), reproductive group between 20 to 44 year (group B) and perimenopausal/postmenopausal group aged 45year and above (group C). The data collected were expressed as mean \pm S.D.

Results: The distribution of cases was as follows: 29 cases (16.38\%) in group A with a mean age of $15.5 \pm 2.21$ years, 97 cases $(54.80 \%)$ in group B with a mean age of $24.20 \pm 4.38$ years and 51 cases $(28.81 \%)$ in group C with a mean age of $46.75 \pm 9.11$ years. Pain was in right lower quadrant $(36.70 \%)$, in left lower quadrant $(27.95 \%)$, suprapubic $(19.35 \%)$ and diffuse (16\%). The most common etiology of APP were as follows: simple ovarian cysts in $16.9 \%$ patients followed by ectopic pregnancy $(15.2 \%)$, complication of uterine fibroid $(10.7 \%)$, rupture ovarian of cysts $(9.7 \%)$ and haemorragic ovarian cysts $(6.8 \%)$. Modality of management in all of the groups was as follows: observation in $21.5 \%$, medical in $25.4 \%$ and surgical in $53.1 \%$.

Conclusions: Accurate clinical and laboratory evaluation are essential in gynecological emergencies. There should be a high index of suspicion for early detection and early intervention to reduce morbidity and mortality.

Keywords: Acute pelvic pain, Gynaecological emergencies, Morbidity, Mortality

\section{INTRODUCTION}

Gynaecological disorders are a common cause of morbidity worldwide with pelvic pain and vaginal bleeding are the most frequent symptoms reported by women during emergency visits. ${ }^{1}$ Acute pelvic pain (APP) accounts for about $40 \%$ of consultation to gynecologic emergency departments. ${ }^{2}$ Generally, it is experienced in the lower abdomen or pelvis and lasts less than three months. It is nonspecific and can be confused with signs of many other diseases. ${ }^{3}$ These emergencies can be classified into two categories in relation with pregnancy. Pregnancy related gynaecological emergencies are mainly complications of early pregnancy 
namely abortion and its complications and abnormal pregnancy includes complicated ectopic and molar pregnancy. Non-pregnancy related emergencies includes haemorrhagic ovarian cysts, adnexal torsion, acute pelvic inflammatory disease (PID), tubo-ovarian abscess, menstrual disorders, bleeding from gynaecological malignancies, vulvovaginal trauma and coital laceration. Most gynaecologic emergencies arise from benign rather than malignant etiologies. Adnexal pathologies are prominent in patients with APP complaints. ${ }^{4-6}$ Specially in old age, these adnexal masses have potential for malignancy so early detection and appropriate management of these acute conditions may decrease morbidity and mortality. ${ }^{7}$

The aim of present study was to analyse etiologic factors of APP at different age group (adolescence, reproductive age and perimenopausal/menopausal periods) to have an overview of emergency gynaecological conditions and their management.

\section{METHODS}

Present study was conducted in Kamineni Institute of Medical Sciences, Narketpally, Nalgonda, Telangana state, India after taking approval from ethical committee, from January 2013 to August 2015. It was a retrospective observational study conducted on 177 women who attended gynaecology outpatients and emergency department with complaint of acute pelvic pain after excluding 79 patients with non-gynecologic etiology.

\section{Inclusion criteria}

- All age group of women (adolescence, reproductive, perimenopausal and postmenopausal).

- Acute pelvic pain of less than 3 months.

- Complicated ectopic and molar pregnancy.

\section{Exclusion Criteria}

- Normal pregnancy and postpartum complication (endometritis).

We retrospectively analyzed medical records of all admitted patients. A detail gynecological history including age, onset, duration and distribution of pain, menstrual history, accompanying symptoms were obtained. A thorough general physical examination including severity of pallor and vital data followed by systemic examination was done. Abdominal examination was done to assess distension of abdomen, any tenderness, guarding, rigidity and rebound tenderness. Any mass was examined in terms of size, consistency, surface, margins, mobility and extent of lower pole. Bimanual pelvic examination was done to assess cervical tenderness, any adnexal mass, tenderness or thickening, status of uterus was assessed by its size, position, mobility, surface contour, consistency etc. In unmarried females per rectal examination was done instead of pelvic examination.

All cases were investigated by haemoglobin percentage, total leucocyte count, differential leucocytes count, blood grouping, routine urine examination, urine pregnancy test and serology. Other laboratory investigations like blood sugar both fasting and postprandial, renal profile, liver profile, coagulation profile and thyroid profile were done where ever indicated. Also patients were subjected to radiological investigations like ultrasonography, CT scan and MRI wherever necessary.

The patients were divided into three groups depending on age, adolescent group patients aged 19 year and below (group A), reproductive group between 20 to 44 year (group B) and perimenopausal/postmenopausal group aged 45 year and above (group C). They were analyzed in terms of mean age of presentation, localizations of pelvic pain, etiological factors and modality of treatment. Statistical analysis was done by tabulating in Microsoft Excel sheet and were expressed as mean \pm S.D.

\section{RESULTS}

During study period 177 patients were consulted for acute pelvic pain. The distribution of cases were as follows: 29 cases $(16.38 \%)$ in group A with a mean age of 15.5 \pm 2.21 years, 97 cases $(54.80 \%)$ in group B with a mean age of $24.20 \pm 4.38$ years and 51 cases $(28.81 \%)$ in group $C$ with a mean age of $46.75 \pm 9.11$ years (Table 1 ).

Table 1: Age wise distribution of study groups $(\mathrm{N}=177)$.

\begin{tabular}{|llll|}
\hline Characteristics & $\begin{array}{l}\text { Adolescent } \\
\text { group }\end{array}$ & $\begin{array}{l}\text { Reproductive } \\
\text { group }\end{array}$ & $\begin{array}{l}\text { Peri and post- } \\
\text { menopausal } \\
\text { group }\end{array}$ \\
\hline $\begin{array}{l}\text { Age in years } \\
(\text { mean } \pm \text { SD })\end{array}$ & $15.5 \pm 2.21$ & $24.20 \pm 4.38$ & $46.75 \pm 9.11$ \\
\hline
\end{tabular}

The duration of pain was ranged between one to 90 days prior to admission to the hospital.

Pain was in right lower quadrant $(36.70 \%)$, in left lower quadrant (27.95\%), suprapubic (19.35\%) and diffuse (16\%) (Table 2).

The most common etiology of APP was as follows: simple ovarian cysts $(16.9 \%)$ followed by ectopic pregnancy (15.2\%), complication of uterine fibroid $(10.7 \%)$, rupture ovarian of cysts $(9.7 \%)$ and haemorragic ovarian cysts $(6.8 \%)$.

Table 2: Localizations of pelvic pain in overall population.

\begin{tabular}{|llcc|}
\hline $\begin{array}{l}\text { Right lower } \\
\text { quadrant }\end{array}$ & $\begin{array}{l}\text { Left lower } \\
\text { quadrant }\end{array}$ & Suprapulbic & Diffuse \\
\hline $36.70 \%$ & $27.95 \%$ & $19.35 \%$ & $16 \%$ \\
\hline
\end{tabular}


Complicated ovarian cyst, benign ovarian neoplasm, complicated tubo-ovarian mass and mullerian anomaly were observed in adolescent group. Complicated ovarian cyst, ovarian hyperstimulation syndrome (OHSS), benign ovarian neoplasm, complicated tubo-ovarian mass, complicated PID, endometriosis, complicated uterine fibroid, ectopic and molar pregnancy were observed in reproductive group. Complicated ovarian cyst, ovarian neoplasm both benign and malignant, complicated tuboovarian mass, complicated PID, complicated uterine fibroid were observed in perimenopausal/postmenopausal groups (Table 3).

Table 3: Distribution of etiology of acute pelvic pain $(\mathrm{N}=177)$.

\begin{tabular}{|c|c|c|c|c|c|c|c|}
\hline \multirow{2}{*}{ Diagnosis } & & & \multirow[b]{2}{*}{$\begin{array}{l}\text { Adolescent } \\
\text { group } \\
(\mathbf{n = 2 9})\end{array}$} & \multirow[b]{2}{*}{$\begin{array}{l}\text { Reproductive } \\
\text { group } \\
(\mathbf{n}=97)\end{array}$} & \multirow{2}{*}{$\begin{array}{l}\text { Peri \& } \\
\text { postmenopausal } \\
\text { group } \\
(\mathrm{n}=51)\end{array}$} & \multicolumn{2}{|c|}{ Total patients } \\
\hline & & & & & & No. & $\%$ \\
\hline \multirow{6}{*}{$\begin{array}{l}\text { Ovarian } \\
\text { cyst }\end{array}$} & Simpl & & 11 & 9 & 10 & 30 & $16.9 \%$ \\
\hline & Ovari & torsion & 5 & 4 & 2 & 11 & $6.2 \%$ \\
\hline & Ruptu & of cysts & 4 & 12 & 1 & 17 & $9.7 \%$ \\
\hline & Haem & ragic cysts & 3 & 7 & 2 & 12 & $7.2 \%$ \\
\hline & Infect & & 2 & 3 & 2 & 7 & $3.9 \%$ \\
\hline & Haem & seritoneum & 0 & 1 & 2 & 3 & $1.6 \%$ \\
\hline \multicolumn{3}{|c|}{$\begin{array}{l}\text { Ovarian hyperstimulation syndrome } \\
\text { (OHSS) }\end{array}$} & 0 & 6 & 0 & 6 & $3.4 \%$ \\
\hline \multirow{2}{*}{\multicolumn{2}{|c|}{ Ovarian neoplasm }} & Benign & 2 & 1 & 8 & 11 & $6.2 \%$ \\
\hline & & Malignant & 0 & 0 & 7 & 7 & $3.9 \%$ \\
\hline \multicolumn{3}{|c|}{ Complicated tubo-ovarian mass } & 1 & 4 & 2 & 7 & $3.9 \%$ \\
\hline \multicolumn{3}{|c|}{ Complicated PID } & 0 & 7 & 4 & 11 & $6.2 \%$ \\
\hline \multicolumn{3}{|c|}{ Endometriosis } & 0 & 2 & 0 & 2 & $1.1 \%$ \\
\hline \multicolumn{3}{|c|}{ Complicated uterine fibroid } & 0 & 8 & 11 & 19 & $10.7 \%$ \\
\hline \multicolumn{3}{|c|}{ Mullerian anomaly } & 1 & 0 & 0 & 1 & $0.5 \%$ \\
\hline \multicolumn{3}{|c|}{ Ectopic pregnancy } & 0 & 27 & 0 & 27 & $15.2 \%$ \\
\hline \multicolumn{3}{|c|}{ Molar pregnancy } & 0 & 6 & 0 & 6 & $3.4 \%$ \\
\hline
\end{tabular}

Table 4: Modality of management in overall population $(\mathrm{N}=177)$.

\begin{tabular}{|c|c|c|c|c|c|}
\hline \multirow{2}{*}{$\begin{array}{l}\text { Modality of } \\
\text { management }\end{array}$} & \multirow{2}{*}{$\begin{array}{l}\text { Adolescent group } \\
(\mathrm{n}=29)\end{array}$} & \multirow{2}{*}{$\begin{array}{l}\text { Reproductive group } \\
(\mathbf{n}=97)\end{array}$} & \multirow{2}{*}{$\begin{array}{l}\text { Peri and postmenopausal group } \\
(\mathrm{n}=51)\end{array}$} & \multicolumn{2}{|c|}{ Total patients } \\
\hline & & & & No. & $\%$ \\
\hline Observation & 9 & 19 & 10 & 38 & $21.5 \%$ \\
\hline Medical & 6 & 31 & 8 & 45 & $25.4 \%$ \\
\hline Surgical & 14 & 47 & 33 & 94 & $53.1 \%$ \\
\hline
\end{tabular}

Modality of management in all of the groups was as follows: observation in $21.5 \%$, medical in $25.4 \%$ and surgical in $53.1 \%$ (Table 4).

\section{DISCUSSION}

Present study was designed to have an overview of emergency gynecological conditions and their management. In present study, the most common cause of APP in all three groups was ovarian cysts and related complications (rupture, torsion etc.) which are similar to others. ${ }^{8-10}$ Although many ovarian cycts are physiologic, the age is an important factor for the possibility of malignancy. At both ends of the reproductive period (menarche and pre-postmenopausal periods) the probability of ovarian malignancy increases. Due to increased incidence of functional cysts with menarche, malignant neoplasms are rare in adolescents. The assessment of the etiology and choice of treatment of pelvic pain in adolescent patients requires care and vigilance. Among ovarian cysts that are frequently seen in this period, are usually simple functional cysts and they disappear by themselves following a few menstrual cycles. $^{4}$ Therefore, conservative approach is appropriate. ${ }^{10-12}$ Adnexal masses in adolescent period reported as benign and non-neoplastic similar to others. $^{10,13}$ Another condition not to be overlooked in the adolescent period is Mullerian anomalies. It should be examined, particularly in presence of progressive pelvic pain or renal agenesis (due to developmental coupling of 
urinary and genital system in embryonic stage) following first menstruation. ${ }^{14}$

Similarly in reproductive age group most common pathology was ovarian in origin which is corresponds with the study done by Kurt $\mathrm{S}$ et al, the rates of APP causes were $48.19 \%$ for ovarian cysts and rupture, $26.86 \%$ for pelvic infections, and $5.81 \%$ for ectopic pregnancies. ${ }^{10}$ In a study by Yenicesu et al these rates were $33.6 \%, 23.2 \%$ and $26.8 \%$ respectively. ${ }^{15}$ In present study, incidence of ectopic pregnancy was $15.2 \%$ in reproductive age group. In developing countries, ectopic pregnancy is the most common surgical gynecological emergency, which is a life-threatening and a leading cause of maternal morbidity and mortality in the early half of pregnancy. ${ }^{16,17}$ The increase in ectopic pregnancies over the last three decades has recently plateaued. ${ }^{18}$ This is because of advances in ultra-sonography technology and its widespread use in early pregnancies, presence of sensitive $\beta$-hcg and progesterone level measurement raised awareness among patients, ectopic pregnancy cases are diagnosed earlier and treated with conservative medical method. ${ }^{18}$

In perimenopausal/menopausal periods, when an adnexal mass is detected as etiology of APP, the malignity potential should be assessed using tumor markers and advanced imaging techniques (CT and MRI). They are also important in gynecologic and non-gynecologic differential etiology. Various degenerations that emerge in the myomas can also be the cause of pelvic pain. ${ }^{19}$ Although pelvic infection and tubo-ovarian abscess are observed less in this period.

In present study modality of treatment in all of the groups were as follows: observation in $21.5 \%$, medical management in $25.4 \%$ and surgical management in $53.1 \%$. Ovarian cysts that are painful may be as a result of torsion, which may present with episodes of recurrent pain over a long period as the pedicle twists and untwists. Finally it becomes continuous as the ovarian blood supply is cut off resulting in gangrene (Figure 1).

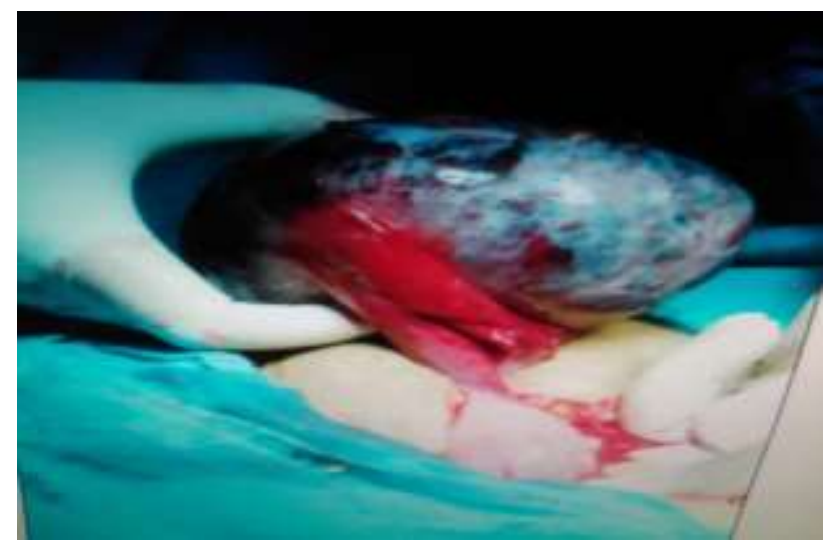

Figure 1: 17 years adolescent with gangerenous ovarian torsion.
Detorsion can be used in young women to preserve ovarian function. $93 \%$ of detorted ovaries will regain normal function. Salpingo-oophorectomy should be done if there is a concern of malignancy or tissue is gangrenous. ${ }^{15}$

Other complication like haemorrhage, rupture, be endometriotic or cancerous. Such patients should be managed in a hospital and they require emergency surgery, usually a laparotomy. Conservative surgery (cystectomy) is usually carried out, but sometimes ovarectomy is done. However conservative management is indicated in patients with Von Willebrands disease or known haemophiliac presenting with haemorrhagic ovarian cyst and patients with ovarian hyperstimulation syndrome (OHSS).

Laparoscopy may also be used to diagnose ectopic pregnancy but fails to detect early ectopic pregnancies or those obscured by adhesion. In such cases diagnostic mini-laparotomy should be done. Surgery (laparoscopy or laparotomy) remains the mainstay of treatment. ${ }^{16}$

The most important aspect with PID is prevention. Primary prevention includes education of the cause of PID and use of condoms and chemical barrier methods. Secondary prevention involves screening women at high risk for chlamydia and gonorrhea, screening for acute cervicitis, treating sexual partners and education to prevent recurrent infection.

Tubo-ovarian abscess is usually associated PID. It is central to the diagnosis and management of tubo-ovarian abscess. Ultrasound is unable to clearly define the borders of the ovaries and fallopian tubes; these structures are thus described as the tubo-ovarian complex. Analgesia, intravenous fluids and antibiotics are required. Prompt surgical intervention should be employed in patients with ruptured tubo-ovarian abscess with generalized peritonitis and septic shock. Ultrasoundguided drainage, colpotomy, percutaneous drainage, ultrasound-guided transvaginal aspiration have been described (Figure 2). ${ }^{20}$

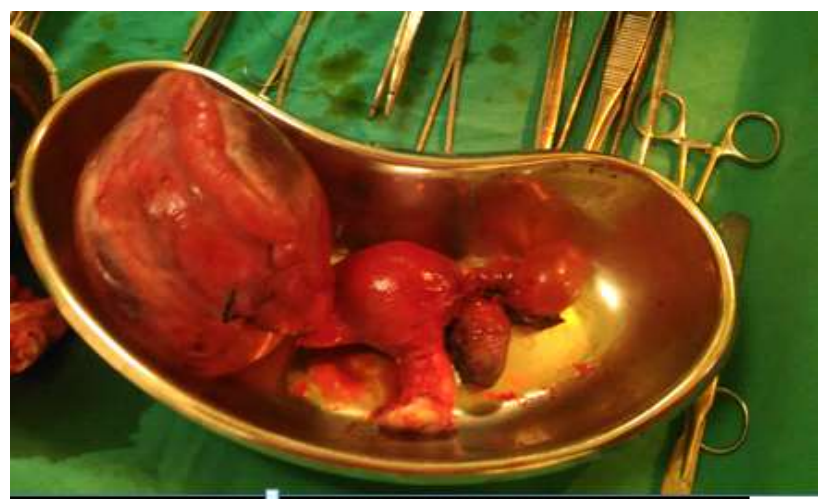

Figure 2: 37 years with complicated tubo-ovarian mass. 
Therefore, diagnosis is based on detailed history of presenting complaint; full gynecological history, clinical symptoms and signs, thorough physical examination and investigations will assist in making accurate diagnosis. Early and accurate diagnosis of APP will often enable more effective and conservative treatment methods for life-threatening pathologies.

\section{CONCLUSION}

From present retrospective analysis it is concluded that accurate clinical and laboratory evaluation are essential in gynecological emergencies. There should be a high index of suspicious for early detection and early intervention to reduce morbidity and mortality. All these emergencies can be treated effectively with basic healthcare resources.

The main objective of gynaecological emergency care services is to identify patients at high risk which poses a potential threat to their life or fertility and management is aimed at the preservation of life, sexual function and fertility.

\section{ACKNOWLEDGEMENTS}

The authors would like to show their deep gratitude to all patients, to Dr. Shruti Mohanty Principal, Dr. G Amaresh Medical superintendent and Dr. Anatha Reddy for their support. And also to authors/editors/publishers of all those articles, journals and books from where the literature for this article has been reviewed and discussed.

\section{Funding: No funding sources}

Conflict of interest: None declared

Ethical approval: The study was approved by the Institutional Ethics Committee

\section{REFERENCES}

1. Walker JW. Abdominal and pelvic pain. Emerg Med Clin North Am. 1987;5:425-8.

2. Kontoravdis A, Chryssikopoulos A, Hassiakos D, Liapis A, Zourlas PA. The diagnostic value of laparoscopy in 2365 patients with acute and chronic pelvic pain. International J Gyn Obs. 1996,52(3):243-8.

3. Steege JF. Pelvic pain phenotyping: the key to progress. Obstet Gynecol. 2009;113:258-9.

4. Vandermeer FQ, Wong JJ. Imaging of acute pelvic pain. Clin Obstet Gynecol. 2009;52(1):2-20.

5. Kruszka PS, Kruszka SJ. Evaluation of acute pelvic pain in women. Am Fam Physician. 2010;82(2):1417.
6. Cuevas C, Dubinsky TJ. Imaging evaluation of acute pelvic pain in reproductive age women: what is the best study? Ultrasound Q. 2011;27(3):211-3.

7. Read MD, Bigrigg MA. The management of gynaecological emergencies. Curr Obs Gyn. 1994;4:98-103.

8. Potter AW, Chandrasekhar CA. US and CT evaluation of acute pelvic pain of gynecologic origin in non-pregnant premenopausal patients. Radiographics.2008;28(6):1645-59.

9. Rapkin AJ, Pelvic pain and dysmenorrhea. In: Berek JS, Adshi EY, Hillard PA. Novak's Gynecology, $13^{\text {th }}$ edition. Pennsylvania; 2004:399-403.

10. Kurt S, Uyar I, Demirtas O, Celikel E, Beyan E, Tasyurt A. Acute pelvic pain: evaluation of 503 cases. Arch Iran Med. 2013;16(7):397-400.

11. Grover S. Pelvic pain in the female adolescent patient. Aust Fam Physician. 2006;35(11):850-3.

12. Gaitan H, Angel E, Sanchez J, Gomez I, Sanchez L, Agudelo C. Laparoscopic diagnosis of acute lower abdominal pain in women of reproductive age. Int $\mathbf{J}$ Gynaecol Obstet. 2002;76(2):149-58.

13. Van WJT, Simmons PS, Podratz KC. Surgically treated adnexial masses in infancy, childhood, and adolescence. Am J Obstet Gynecol. 1994;170(6):1780-6.

14. Del VR, Battisti S, Di Paola V, Piccolo CL, Cazzato RL, Sansoni I, et al. Herlyn-werner-wunderlich syndrome: MRI findings, radiological guide (two cases and literature review), and differential diagnosis. BMC Med Imaging. 2012;12:4.

15. Yenicesu C, Imir G, Cetin M, Kuckukozkan T. Evaluation of the treatment modalities and hospitalization period in patients with acute pelvic pain related to adnexal pathologies. CU Journal of Medicine. 2008;30(1):1-7.

16. Olarewaju RS, Ujah IAO, Otubu JAM. Trends in ectopic pregnancy in the Jos university teaching hospital, Jos, Nigeria. Nig J Med. 1994,26:57-60.

17. Grimes DA. The morbidity and mortality of pregnancy. Still risky business. Am J Obstet Gynecol. 1994;170:1489-94.

18. Kurt S, Demirtas O, Gurbuz T, Aldemir OS, Bicer H,Tasyurt A. Management of ectopic pregnancy. Retrospective analysis of 171 cases. Turkiye Klinikleri J Gynecol Obst. 2012;22(2):84-9.

19. Nyapathy V, Polina L. MRgFUS treatment of uterine fibroid in a nulliparous woman with acute retention of urine. Radiol Case. 2012;6(2):1-8.

20. Samraj GP, Curry RW Jr. Acute pelvic pain: evaluation and management. Compr Ther. 2004;30:173-84.

Cite this article as: Choudhary V, Somani SS, Somani SG, Kaul R. Evaluation of series of 177 cases of acute gynaecological emergencies in tertiary care hospital. Int J Reprod Contracept Obstet Gynecol 2016;5:1700-4. 